
Dé
DOE/ER/14035- -T2
Summary of Progress
DE93 005917

\section{HIGH PRESSURE HETEROGENEOUS CATALYSIS IN A LOW PRESSURE ULTRAHIGH VACUUM ENVIRONMENT}

\author{
S. T. Ceyer \\ DE-FG02-89ER14035 \\ July 1, 1989 - December 31, 1992
}

The major thrust of our research is to carry out heterogeneous catalytic reactions that are normally observed only at high pressures of reactant gas at low pressures in an ultrahigh vacuum environment. These studies have now become possible because of the development of new physical processes and techniques in our laboratory over the last five years: the synthesis of adsorbed, reactive intermediates by translational and collision induced activation, collision induced absorption, collision induced recombinative desorption and bulk vibrational spectroscopy. These new processes allow the simulation of a high pressure environment while maintaining the single collision conditions in which microscopic reaction steps and intermediates can be elucidated and detected by molecular beam scattering coupled with high resolution electron energy loss spectroscopy.

Our first funding period of this project brought sufficient funds to construct the main chamber of the apparatus on which these experiments will be carried out. A schematic of the apparatus, which couples the technologies of high resolution electron energy loss spectroscopy with molecular beam and scattering techniques, is shown in Fig. 1. It consists of two, triply, but individually differentially pumped, supersonic molecular beam sources. One of the beam sources, along with its differential chambers, rotates so that angular distributions of molecules scattered from the surface can te measured. The beam is collimated to $10^{-4} \mathrm{sr}$ by a set of slits in the walls of the differential pumping chambers before it enters into the UHV main chamber where it is incident on the $\mathrm{Ni}$ surface. The intensity of the beams on the crystal is about $10^{4}$ times larger than the intensity from the background. The Ni crystal is mounted on a manipulator which allows the crystal to be cooled to $8 \mathrm{~K}$, heated, rotated $360^{\circ}$ around an axis parallel to its surface 


\section{DISCLAIMER}

This report was prepared as an account of work sponsored by an agency of the United States Government. Neither the United States Government nor any agency thereof, nor any of their employec:, makes any warranty, express or implied, or assumes any legal liability or responsibility for the accuracy, completeness, or usefulness of any information, apparatus, product, or process disclosed, or represents that its use would not infringe privately owned rights. Reference herein to any specific cornmercial product, process, or service by trade name, trademark, manufacturer, or otherwise does not necessarily constitute or imply its endorsement, recommendation, or favoring by the United States Government or any agency thereof. The views and opinions of authors expressed herein do not necessarily state or reflect those of the United States Government or any agency thereof. 
and translated in 3 mutually perpendicular directions. The manipulator is mounted eccentrically on a 15 " differentially pumped rotatable flange. Rotation of this flange allows the crystal to be positioned in front of the Auger CMA, LEED or HREEL spectrometer or to intercept the beam at the scattering center. When the crystal is positioned at the scattering center, the scattered inolecules are detected by a triply differentially pumped quadrupole mass spectrometer. A chopper positioned at the entrance to the first differential stage of the detector is used for time of flight measurements of the scattered beam. The chopper motor is mounted in its own differentially pumped chamber. The flight path is about $20 \mathrm{~cm}$.

Given the demanding technical requirements associated with our scientific goals, the apparatus is large ( 3 tons, $\left.3^{\prime} \times 4^{\prime} \times 4^{\prime}\right)$ and complex. One of the requirements in the fabrication of the apparatus is that the machining of the chambers be done after all wclding on the chamber is complete. This procedure is necessary to insure the stringent alignment conditions for the molecular beams and it is this requirement that adds substantially to the complexity of the design and manufacture of the apparatus. In addition, our original proposal presented a long-range program of research that encompasses investigations into many conceivable mechanisms for high pressure reactions. Appropriately then, much of our effort has been invested in the design and construction of an apparatus suitable to impleme.tt this broad program of research. We have made good progress on the construction of the main chamber and expect delivery by the end of this year. - i the meantime, we have been carrying out investigations on a class of high pressure reactions called hydrogenation reactions. These reactions have less demanding technical requirements and therefore, they can be probed on an existing apparatus, which has facilities for a single molecular beam, electron spectroscopy and thermal desorption.

Using molecular beam techniques coupled with high resolution electron energy loss spectroscopy, we have recently demonstrated the synthesis and detection of 
hydrogen embedded in the bulk of Ni under low pressure, UHV conditions. These capabilities have enabled the chemistry of bulk hydrogen to be probed unambiguously for the first time. We have found that the bulk hydrogen atom has unique chemistry. In particular, we have shown that the species reactive with adsorbed $\mathrm{CH}_{3}$ is not a surface bound $\mathrm{H}$ atom but a bulk $\mathrm{H}$ atom.

The experiment is performed as follows. Exposure of the Ni(111) crystal to atomic hydrogen not only results in hydrogen embedded within the Ni lattice but also in a monolayer of hydrogen adsorbed on the surface. The surface-bound hydrogen is a problem because it blocks sites necessary for the second reactant, adsorbed $\mathrm{CH}_{3}$, that we synthesize by the dissociative chemisorption of $\mathrm{CH}_{4}$. Therefore, the $\mathrm{H}$ adsorbed on the surface must be removed. The removal of the surface-bound $\mathrm{H}$ cannot be effected thermally because it is more stable than bulk $\mathrm{H}$, recombining and desorbing between 340 $-390 \mathrm{~K}$. Therefore, removal of the surface-bound $\mathrm{H}$ by the non-thermal process, collision induced recombinative desorption, is necessary. A $100 \mathrm{kcal} / \mathrm{mol} \mathrm{Xe}$ atom beam is directed at the surface at a glancing angle. The impacts of the Xe atoms deform the surface and allow the hydrogen to recombine and desorb as $\mathrm{H}_{2}$. In this manner, the surface is swept clean of hydrogen while the bulk hydrogen remains. The clean surface is then exposed to $\mathrm{CH}_{4}$ incident at $17 \mathrm{kcal} / \mathrm{mol}$. The $\mathrm{CH}_{4}$ dissociatively adsorbs, producing adsorbed $\mathrm{CH}_{3}$ and adsorbed hydrogen. With the reactants now synthesized, the surface temperature is ramped at $2 \mathrm{~K} / \mathrm{s}$ and the partial pressures of hydrogen and methane are measured. At exactly the same temperature at which hydrogen desorbs from the bulk, $180 \mathrm{~K}$, there is very intense desorption of $\mathrm{CH}_{4}$. We have also carried out this reaction with the deuterium isotope embedded in the $\mathrm{Ni}$ lattice. In this case, the sole product observed is $\mathrm{CH}_{3} \mathrm{D}$. There is no formation of $\mathrm{CH}_{4}$ or higher deuterated methanes. In the absence of bulk hydrogen, no $\mathrm{CH}_{4}$ is observed to desorb.

Methane is formed solely by the reaction with bulk hydrogen. The surface bound hydrogen is unreactive with $\mathrm{CH}_{3}$. The reaction likely proceeds by the direct 
recombination of a bulk $\mathrm{H}$ atom with $\mathrm{CH}_{3}$ because the interstitial octahedral site in which the hydrogen atom is bound is directly beneath the threefold hollow site on which the $\mathrm{CH}_{3}$ is bound. As the surface temperature is raised, the bulk hydrogen atom moves up toward the surface where it encounters the methyl radical. Because the hydrogen atom now has the correct orientation required by the transition state for $\mathrm{sp}^{3}$ hybridization, it reacts with $\mathrm{CH}_{3}$ and immediately desorbs as $\mathrm{CH}_{4}$. The reaction of $\mathrm{CH}_{3}$ with an adsorbed $\mathrm{H}$ atom probably does not occur because access of the $\mathrm{H}$ atom to the $\mathrm{Ni}_{3}-\mathrm{C}$ bond is blocked.

This result was recently published in Science 257, 223 (1992). It documents a new mechanism for a surface reaction, a reaction between an adsorbed and a bulk species, and it unambiguously demonstrates the importance of bulk hydrogen as a reactant in a heterogeneous catalytic reaction.

\section{Publications}

The Chemistry of Bulk Hydrogen: Reaction of $\mathrm{H}$ Embedded in $\mathrm{Ni}$ with Adsorbed $\mathrm{CH}_{3}$ A. D. Johnson, S. P. Daley, A. L. Utz and S. T. Ceyer

Science 257, 223 (1992)

\section{Ph.D. Thesis}

\section{A. D. Johnson}

"Dynamics of Hydrogen Absorption into the Ni(111) Bulk: Spectroscopic Identification and Chemistry of Subsurface Hydrogen"

February, 1991

We acknowledge DoE funding for partial support of this thesis.

This thesis was recently awarded the LaMer Award from the Division of Colloid and Surface Chemistry, American Chemical Society.

This thesis was also awarded the Nobel Laureate Signature Award for the best Ph.D. thesis in chemistry by the American Chemical Society. 


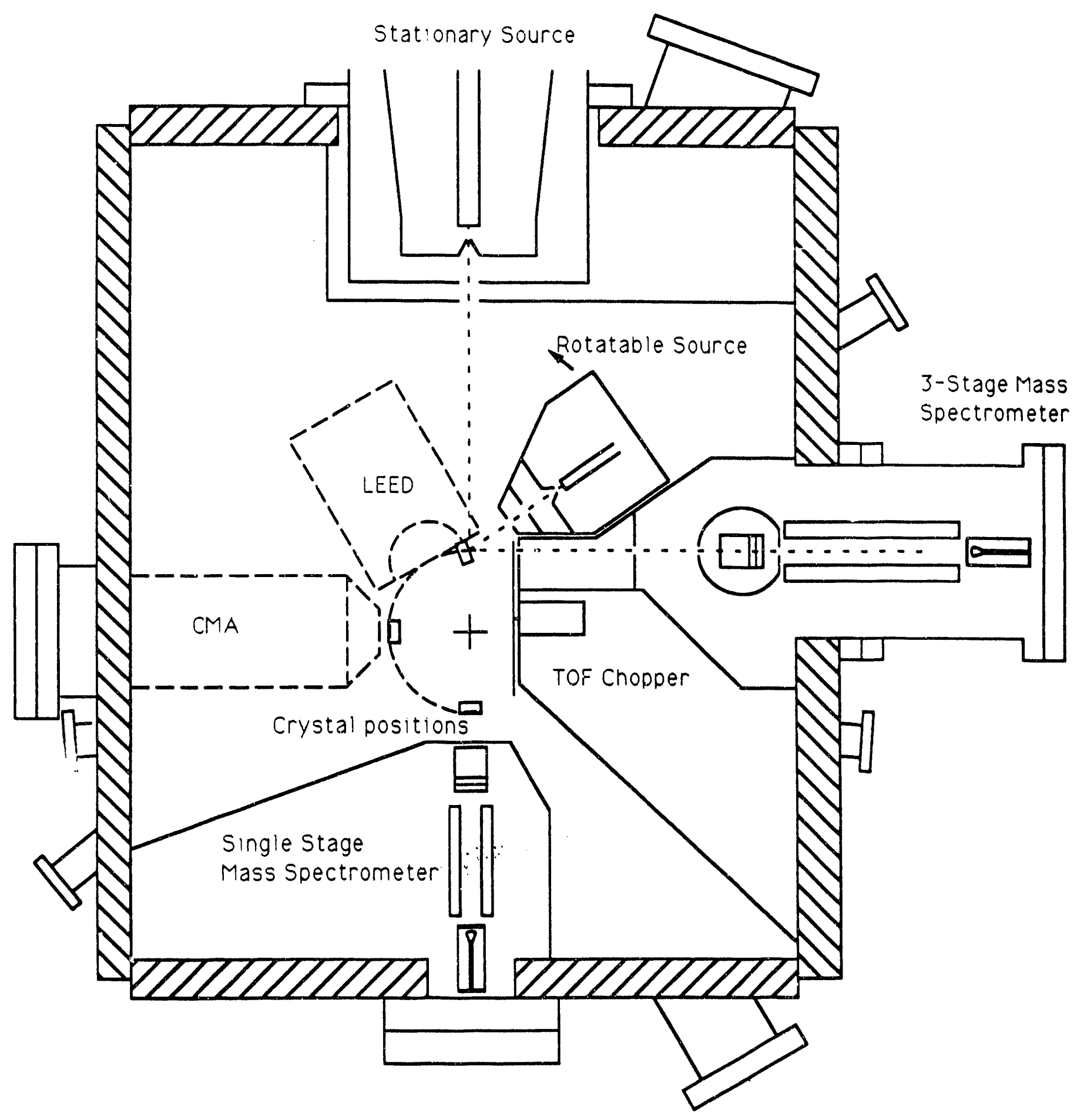

Figure 1 
DATE

FILMED

214193 


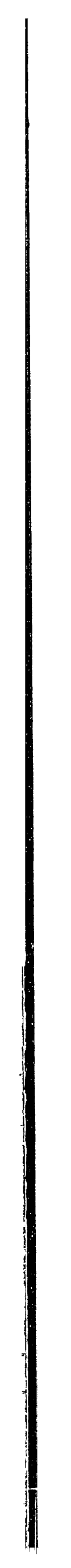

